\title{
INTEGRACIÓN DE LAS FUNCIONES SUSTANTIVAS EN EL PROCESO DE ENSEÑANZA Y APRENDIZAJE
}

\author{
Cristina Juárez de Amaya \\ Vicerrectora Académica \\ Universidad Evangélica de El Salvador
}

La encomienda que la Ley de Educación Superior determina para las Instituciones de Educación Superior (IES), se resume en los objetivos que promueve para este nivel educativo: a) formar profesionales competentes con fuerte vocación de servicio y sólidos principios morales; b) promover la investigación en todas sus formas; c) prestar un servicio social a la comunidad;d) cooperar en la conservación, difusión y enriquecimiento del legado cultural en su dimensión nacional y universal.

La reflexión sobre los desafíos que enfrenta el nivel de educación superior no puede idearse de manera desarticulada de los niveles que lo anteceden, debido a que la calidad de la educación de una nación exige un análisis del sistema educativo en su conjunto. Un avance del país que se debe resaltar, es que en los últimos años se ha comenzado a dar atención al nivel de educación inicial, que cobra relevancia si partimos de que la educación es un proceso de formación permanente, personal, cultural y social que se fundamenta en una concepción integral de la persona humana, de su dignidad, de sus derechos y de sus deberes. Eso nos lleva a considerar que las actividades investigativas y de servicio social deberían estar presentes como un eje transversal de la educación en los diferentes niveles del sistema educativo; es decir, desde su nivel inicial, el sistema educativo podría alentar el desarrollo del pensamiento crítico en el estudiante, donde el niño y la niña sean capaces de descubrir y comenzar a analizar las diferentes realidades que les rodean.

Poniendo en perspectiva esta realidad nacional, ¿qué oportunidades tenemos como Universidad para asegurar la formación de profesionales competentes que respondan a las necesidades sociales del país?, ¿cómo podremos despertar en el estudiante universitario su vocación de servicio y el interés por la investigación?

Para iniciar el debate académico sobre estos planteamientos, cabe destacar que nuestra Universidad ha dado pasos acertados en esta dirección. Por citar algunos:

- Se cuenta con las Políticas de Investigación y Proyección Social, las cuales actualmente se encuentran en proceso de actualización.

- Se dispone del Reglamento del Ejercicio de la Docencia y de la Política Curricular, lineamientos que promueven y definen mecanismos para la integración de las funciones sustantivas.

- Se han diseñado de manera integrada las Líneas Institucionales de Investigación-Proyección Social-Difusión, en consonancia con los Planes de Estudios de cada disciplina y áreas temáticas establecidas por el Ministerio de Educación.

- La creación del Sello Editorial de la UEES ha potenciado la publicación de manuales de cátedra, libros, colecciones, revistas indexadas y anuarios de investigación.

- El diseño curricular de las carreras de pregrado ha contemplado al menos dos asignaturas básicas relacionadas con metodología de la investigación.

- Desde la Vicerrectoría de Investigación y Proyección Social, la Universidad implementa el programa de formación permanente de investigadores. 
- Desde la Escuela de Posgrados, se ofertan programas de educación continua: Diplomado en Investigación Científica (modalidad virtual) y Maestría en Metodología de la Investigación Científica (modalidad semipresencial).

En reconocimiento a estos esfuerzos, y en pro de la mejora continua, como UEES necesitamos continuar avanzando con la transformación del currículo en las diferentes carreras, pero además, al interior de cada programa, se deberá fortalecer la integración de las funciones sustantivas con las funciones adjetivas (gestión administrativa), de manera que la Institución en su conjunto responda a los requerimientos que conlleva la integración de la docencia-investigaciónproyección social-difusión en las actividades curriculares y extracurriculares.

Elementos como el modelo educativo, el sello institucional, la política curricular, el reglamento para el ejercicio de la docencia y las políticas de investigación y proyección social, son puntos de partida relevantes; asimismo, no podemos obviar que la Misión y la Visión Institucional son nuestros amplios referentes, y el más concreto de ellos es el Perfil del Egresado. Éste es el referente fundamental de las intenciones institucionales y debe definir con claridad los atributos de información (conocimientos), formación (actitudes y valores) y capacitación (aptitudes y habilidades) que el estudiante será capaz de mostrar al término de su proceso de enseñanza y aprendizaje. Es la declaración de la intención más concreta que guía las acciones de quienes la deben de cumplir: a los profesores, los guía en cuánto a lo que deben lograr que el estudiante alcance; y a los estudiantes, les informa de los atributos a que se compromete la Institución inculcarles a lo largo de sus estudios.

Los perfiles de egreso cumplen la función de ser el parámetro para evaluar el logro en los egresados, por tanto no deben ser sólo genéricos, sino específicos y deben ser congruentes con la Misión, Visión, modelo educativo y concepción del proceso de enseñanza y aprendizaje (COPEA) de cada disciplina.

Los retos que enfrentan los procesos de diseño curricular desde el enfoque por competencias implican la transformación gradual de la Universidad en su conjunto: superestructura-estructurainfraestructura; involucra entrar en un análisis sobre cómo se concibe que se aprende y se enseña una disciplina, la forma en la que se debe enseñar y aprender: "Estrategias metodológicas". Es aquí donde la planificación didáctica de la asignatura es trascendente.

Desde el proceso de enseñanza-aprendizaje, una de las acciones que las IES podemos hacer para formar en el estudiante las competencias relacionadas a las funciones sustantivas es considerarlas dentro de la planificación didáctica, en la medida de las posibilidades de la misma asignatura, de sus temáticas, contenidos, objetivos de aprendizaje, distribución teoría-práctica.

Hacer un inventario de las estrategias metodológicas que se implementan en una asignatura es una buena práctica pedagógica, porque permite al docente confrontar si efectivamente las competencias que el estudiante requiere formar en su cátedra las está logrando o no con las técnicas y estrategias que se implementan: clases magistrales, prácticas de laboratorio, tutorías, club de revista, ensayos, consulta de literatura científica, revisiones bibliográficas, resúmenes analíticos de investigación, estudio de caso, visitas de campo, aprendizaje basado en proyectos sociales, investigación-acciónparticipación, entre otros. Esta diversidad de prácticas promueve un marco de flexibilidad en cuanto que asume que la investigación y la acción social no son realizadas sólo por los expertos, sino que requieren la participación de la comunidad de aprendizaje en todo el proceso (estudiantes, profesores, comunidad social), posicionan como fin que la comunidad de aprendizaje en sí misma sea la gestora del proceso y se apropie de él, asumiendo tanto el control cognitivo (saber) como el operativo (saber hacer). 
Cada docente debe tener claridad sobre la competencia del "Perfil de Egreso" al cuál desde su asignatura está contribuyendo a formar; debe conocer con certeza a cuáles funciones sustantivas responde su asignatura: ¿a la docencia e investigación?, ¿a la docencia y proyección social?, ¿a la docencia y difusión?, ¿a la docencia, investigación y difusión?...

Como bien lo cita nuestra Política Curricular, los procesos de diseño de nuevas carreras y la actualización de carreras vigentes deben mostrar una congruencia y coherencia en torno a cuatro aprendizajes vinculados al desarrollo de competencias: a) aprender a conocer, b) aprender a hacer, c) aprender a ser y d) aprender a convivir juntos. Dicho de otra manera, conforme a las bases del modelo V "Análisis Estructural Integrativo de las Organizaciones Universitarias": Referente Institucional (SER - SELLO), Referente Disciplinario (SABER), Referente Profesional (SABER HACER), Referente Social (SABER PARA QUIÉN SE ES, PARA QUIÉN SE SABE, PARA QUIÉN SE HACE).

Si en verdad aspiramos a que en el aula, y fuera del aula también, nuestros actores principales, "profesor y estudiante", emprendan su contenido disciplinario utilizando métodos y técnicas que circunscriban el desarrollo de prácticas investigativas, de proyección social o de difusión..., y debemos citar entonces éste "quehacer" desde el diseño curricular, y gradualmente ir creando las condiciones superestructurales, estructurales e infraestructurales en cada carrera.

Dispondremos así de un Plan de Estudios que, además de su contenido disciplinario, define claramente sus líneas de investigación, proyección social, difusión, y cuyo seguimiento del Perfil de Egreso se confronta con las competencias que el estudiante logrará a lo largo de su carrera, mediante cada una de las cuatro funciones sustantivas.

Como una Universidad que aspira a la mejora continua, sigamos pues propiciando espacios de reflexión y debates académicos con nuestros docentes, estudiantes y administrativos, para asegurar la consecución de nuestra Misión Institucional, cuyo alcance es responsabilidad de todos:

Formar profesionales con excelencia académica, conscientes del servicio a sus semejantes y con una ética cristiana basada en las Sagradas Escrituras, para responder a las necesidades y cambios de la sociedad. 